\title{
PENGEMBANGAN MODEL PEMBELAJARAN HURUF HIRAGANA DALAM WUJUD CD INTERAKTIF UNTUK SISWA KELAS IV SD
}

\author{
Oleh \\ I Made Marthana Yusa ${ }^{1}$, Fajar Wati Putu Yuliana ${ }^{2}$ \\ Program Studi Teknik Informatika-Konsentrasi Desain Grafis Dan \\ Multimedia \\ STMIK STIKOM Indonesia (STIKI Indonesia) \\ e-mail: made.marthana@yahoo.com ${ }^{1}$, fajar.yuliana@gmail.com²
}

\begin{abstract}
ABSTRAK
Penelitian ini bertujuan untuk menghasilkan media pembelajaran alternatif berbasis komputer yang menarik, dalam pembelajaran bahasa Jepang, untuk siswa kelas IV SD. Media pembelajaran yang dipilih berbentuk CD Interaktif. Materi pembelajaran bahasa Jepang yang dipilih adalah pembelajaran tulisan Hiragana, karena lebih mudah dipelajari jika dibandingkan dengan huruf Katakana dan Kanji. Pembelajarannya meliputi cara penulisan, pengucapan huruf dan pemakaian pada beberapa kata serta arti dari kata tersebut. Model pembelajaran yang penulis gunakan adalah model tutorial dan instructional games. Penyampaian materi pembelajaran huruf Hiragana adalah dengan konsep bercerita (storytelling). Dalam proses pembelajaran dengan CD interaktif model tutorial dan instructional games, dengan konsep storytelling akan membantu anak untuk tidak hanya mengutamakan kemampuan otak kiri yang cenderung berpikir rasional, tetapi juga otak kanan dengan kecenderungan berpikir kreatif dan imajinatif. Secara umum semua anak-anak senang mendengarkan storytelling, baik anak balita, usia sekolah dasar, maupun yang telah beranjak remaja bahkan orang dewasa.
\end{abstract}

Kata Kunci : media pembelajaran, cd interaktif, pembelajaran huruf Hiragana, model tutorial, instructional games

\section{PENDAHULUAN}

\subsection{Latar Belakang}

Pembelajaran bahasa internasional biasanya dimulai dari pendidikan Sekolah Dasar (SD). Sudah banyak SD di Indonesia yang memasukkan bahasa internasional dalam kurikulum pendidikannya. Kondisi berbeda dialami oleh SD Negeri di kawasan kecamatan Kuta Selatan. Kecamatan Kuta Selatan merupakan kawasan pariwisata strategis di Bali. Tidak seperti SD Swasta, belum banyak 
terdapat SD Negeri di Kuta Selatan yang memasukkan bahasa Jepang ke dalam kurikulum pendidikannya. Sesuai hasil survey tim penulis, hanya terdapat tiga SD swasta yang sudah memasukkan bahasa Jepang ke dalam kurikulum pendidikan, salah satunya adalah SD Nusa Dua. SD Nusa Dua memasukkan bahasa Jepang dalam kurikulum sebagai bahasa internasional. Pengajaran bahasa Jepang ini dimulai dari kelas IV SD.

Ogawa (2008) menyampaikan, langkah awal dalam belajar bahasa Jepang adalah mempelajari huruf Hiragana, karena lebih mudah dipelajari jika dibandingkan dengan huruf Katakana dan Kanji. Dalam memberikan pembelajaran huruf Hiragana, ada beberapa unsur penting yang harus diperhatikan oleh peserta didik, salah satunya penulisan dan cara baca atau pengucapan. Dalam penulisan, peserta didik terkadang sulit untuk mengikutinya. Apalagi peserta didik yang memiliki daya pikir dan daya serap yang kurang. Hal tersebut menyebabkan pengajar harus mengulangi penyampaian materi beberapa kali dalam proses pembelajaran konvensional di kelas. Begitu juga dalam hal pengucapan huruf atau kata, pengajar terkadang harus mengulangi beberapa kali pengucapan kata agar peserta didik dapat memahami dan bisa mengikuti dengan baik. Hal seperti ini dapat menyebabkan kurang efisiennya waktu dan tenaga. Disamping itu hasil yang diharapkan kurang memuaskan. Menurut Lembaga Psikologi Episentrum (2010), anak-anak, dalam hal ini siswa kelas IV SD yang rentang usianya antara (9-10 tahun), cenderung lebih senang bermain dibanding belajar.

Untuk menangani permasalahan tersebut, diperlukan media pembelajaran alternatif selain instrumentasi pembelajaran konvensional guna membantu proses belajar mengajar, sehingga motivasi dan pemahaman peserta didik bisa ditingkatkan. Penulis melihat media $\mathrm{CD}$ interaktif bisa menjadi media pembelajaran alternatif bagi pembelajaran huruf Hiragana. Kelebihan menggunakan CD Interaktif, seperti yang disampaikan Reskiwahyudi (2011) adalah selain adanya kemudahan dalam menambah pengetahuan, CD Interaktif memiliki tampilan audio-visual yang lebih menarik dibandingkan dengan pembelajaran konvensional di kelas. Salah satu kelebihan media CD Interaktif juga bisa mengajak siswa untuk bermain sekaligus belajar.

Penelitian ini mencoba mengkaji bagaimana wujud media pembelajaran CD Interaktif yang menyampaikan materi pembelajaran Huruf Hiragana. Aspek-aspek yang diperhatikan adalah cara penyampaian materi sebagai pengembangan penyampaian materi pembelajaran Huruf Hiragana di kelas. Penyampaian materi dikemas dalam wujud yang berbeda, dalam hal ini CD Interaktif.

\subsection{Rumusan masalah}

Masalah utama dalam makalah ini adalah "Bagaimana perancangan CD interaktif pembelajaran huruf Hiragana yang menarik bagi siswa kelas IV SD?"

\subsection{Batasan Perancangan}

Perancangan ini dibatasi pada hal-hal sebagai berikut :

1. Bentuk perancangan media pembelajaran adalah CD interaktif. 
2. Huruf yang dibahas hanya huruf Hiragana, yang pembelajarannya meliputi cara penulisan, pengucapan huruf dan pemakaian pada beberapa kata serta arti dari kata tersebut.

3. Materi pembelajaran huruf Hiragana ini ditujukan untuk siswa kelas IV SD (umur 9-10 tahun).

\subsection{Tujuan}

Penelitian ini bertujuan untuk menghasilkan media pembelajaran alternatif berbasis komputer yang menarik dalam pembelajaran bahasa Jepang untuk siswa kelas IV SD.

\section{KAJIAN PUSTAKA}

\subsection{Pengertian Perancangan}

Penulis memilih kata 'desain' sebagai padanan kata yang tepat untuk kata 'perancangan'. Menurut etimologi, pada Widagdo (2005), desain memiliki beberapa pengertian sebagai berikut : designose (Bahasa Latin) menyebutkan perancangan sebagai tindakan menakik untuk memberi tanda. Maksudnya adalah untuk memberi citra pada objek tertentu; designare (Bahasa Perancis) menyebutkan perancangan sebagai tindakan menandai/memberi penanda, memisahkan, dengan maksud menghilangkan kesimpangsiuran; design (Bahasa Inggris) menyebutkan perancangan adalah memikirkan, menggambar rencana, menyusun bagian-bagian menjadi sesuatu yang baru. Rancangan menurut Chulsum (2006) adalah sesuatu yang telah dirancang, hasil dari rencana. Perancangan pada sebuah sistem adalah proses, cara, agar sebuah sistem dapat berjalan sebagai mana yang diinginkan. Dari pemaparan tersebut, penulis menyimpulkan bahwa perancangan adalah suatu aktifitas memikirkan, menggambar, merencanakan, menyusun sesuatu yang baru dan berguna yang tidak ada sebelumnya.

\subsection{Media Pembelajaran Berbasis Komputer}

Riswan (2009) menyampaikan, bagian dari model pembelajaran berbasis komputer adalah model drills, model tutorial, model simulasi, dan instructional games. Penulis melihat model tutorial dan instructional games sebagai model yang lebih menarik dan sesuai sebagai model pembelajaran untuk siswa kelas IV SD dibandingkan model drills dan simulasi.

\subsubsection{Model Tutorial}

Model pembelajaran tutorial adalah pembelajaran khusus dengan instruktur yang terkualifikasi, penggunaan mikro komputer untuk tutorial pembelajaran. Model pembelajaran tutorial merupakan program pembelajaran yang digunakan 
dalam proses pembelajaran dengan menggunakan software berupa program komputer yang berisikan materi pelajaran. Karakteristik :
a. Adanya panduan yang membimbing siswa
b. Adanya respon dari siswa
c. Respon siswa dievaluasi oleh komputer
d. Melanjutkan atau mengulangi tahapan sebelumnya

\subsubsection{Model Instructional Games}

Instructional games merupakan salah satu bentuk modifikasi dari permainanpermainan (games) yang ada dalam program komputer tetapi pengemasan isi disesuaikan dengan materi pembelajaran. Karakteristik :

a. Setiap permainan harus memiliki tujuan

b. Adanya aturan yang harus diikuti oleh user atau pengguna

c. Adanya suasana kompetisi untuk menempuh tujuan atau target yang dicapai

d. Adanya tantangan untuk menambah daya tarik games

e. Bersifat imajinatif

f. Bersifat menghibur.

\subsection{Media CD Interaktif}

CD Interaktif termasuk dalam media pembelajaran berbasis komputer dan multimedia interaktif. Setemen dkk (2004) menyampaikan, banyak batasan yang diberikan orang tentang media. Asosiasi Teknologi dan Komunikasi Pendidikan (Association of Education and Comunication Technology/EACT) di Amerika misalnya, membatasi media sebagai segala bentuk dan saluran yang digunakan orang untuk menyalurkan pesan/informasi. Briggs pada Setemen dkk (2004) berpendapat bahwa media adalah segala alat fisik yang dapat menyajikan pesan serta merangsang siswa untuk belajar. Buku, film, kaset, film bingkai adalah contoh-contohnya. Sementara menurut Asosiasi Pendidikan Nasional (National Education Association/NEA), media adalah bentuk komunikasi tercetak maupun audiovisual serta peralatannya. Sesuai pendapat tersebut, media yang dimaksud adalah sebuah perangkat lunak yang tersimpan dalam bentuk CD (Compact Disc). Reskiwahyudi (2011) menyampaikan CD Interaktif berasal dari dua istilah yaitu CD dan Interaktif. CD berasal dari bahasa Inggris merupakan singkatan dari Compact Disc, sedangkan interaktif dalam Kamus Besar Bahasa Indonesia (KBBI) diartikan sebagai dialog antara komputer dan terminal atau komputer dengan komputer. Berdasarkan pemaparan teori tersebut, penulis mengambil kesimpulan bahwa CD Interaktif adalah piringan metal yang digunakan sebagai alternatif sumber belajar sehingga dapat merangsang pikiran, perasaan dan minat peserta didik untuk memperhatikan pelajaran yang diberikan oleh pengajar.

Kelebihan menggunakan CD Interaktif, seperti yang disampaikan Reskiwahyudi (2011) adalah selain adanya kemudahan dalam menambah pengetahuan, $\mathrm{CD}$ Interaktif memiliki tampilan audio-visual yang lebih menarik 
dibandingkan dengan pembelajaran konvensional di kelas. Materi pada CD interaktif memiliki tampilan yang lebih kaya dari media konvensional seperti buku atau media cetak lain. Tampilan CD Interaktif lebih kaya karena ada unsur audio, visual, animasi, bahkan video. Keunggulan utama terletak pada interaksi antara media dengan pengguna. Mengenai keunggulan CD Interaktif ini, merupakan salah satu dasar utama pemilihannya sebagai media pembelajaran.

\subsection{Storytelling}

Narasi (storytelling) adalah wahana untuk menyampaikan cerita dengan pesanpesan khusus yang terkandung di dalamnya. Storytelling mengoptimalkan proses kreatif anak-anak yang sedang berkembang, senantiasa mengaktifkan bukan hanya aspek intelektual saja tetapi juga aspek kepekaan, kehalusan budi, emosi, seni, daya berfantasi, dan imajinasi. George W.Burns mengemukakan pada Episentrum (2010) bahwa storytelling atau penyampaian cerita, bisa mengubah cara kita berpikir atau merasa tentang sesuatu, bahkan juga mengubah sesuatu dalam proses pikiran-tubuh kita seperti yang bisa dilihat pada perubahan dalam respirasi, irama otot, dan detak jantung. Ada beberapa kekuatan cerita :

1. Kekuatan cerita untuk menumbuhkan sikap disiplin

2. Kekuatan cerita untuk membangkitkan emosi

3. Kekuatan cerita untuk memberi inspirasi

4. Kekuatan cerita untuk memunculkan perubahan

5. Kekuatan cerita untuk menumbuhkan kekuatan pikiran-tubuh

6. Kekuatan cerita untuk menyembuhkan

Davidson (2004) menyampaikan bahwa cerita juga mempunyai kekuatan untuk membagi pengetahuan dan menjembatani keragaman budaya, bahasa dan usia. Penulis melihat storytelling bisa dipergunakan dalam penyampaian materi. Kekuatan storytelling bisa mengajak pengguna media pembelajaran CD Interaktif untuk terlibat dalam cerita sambil menerima materi. Hal tersebut bisa mengatasi kejenuhan yang biasanya timbul pada penyampaian materi pembelajaran dengan cara konvensional di kelas.

\subsection{Pengaruh Permainan pada Perkembangan Anak}

Jika masih ada orang tua yang berpendapat bahwa bermain terlalu banyak akan membuat anak menjadi malas bekerja dan bodoh, maka orang tua perlu menyimak paparan Lembaga Psikologi Episentrum. Episentrum (2010) menyampaikan, permainan sangat besar pengaruhnya terhadap perkembangan jiwa anak.

\section{Pengaruh bermain bagi perkembangan anak:}

- Bermain mempengaruhi perkembangan fisik anak

- Bermain dapat digunakan sebagai terapi

- Bermain dapat mempengaruhi dan menambah pengetahuan anak 
- Bermain mempengaruhi perkembangan kreativitas anak

- Bermain dapat mengembangkan tingkah laku sosial anak

- Bermain dapat mempengaruhi nilai moral anak

Episentrum (2010) juga memaparkan ada jenis permainan aktif dan jenis permainan pasif. Jenis permainan aktif diantaranya bermain bebas dan spontan, bermain musik, sandiwara, mengumpulkan atau mengoleksi sesuatu, dan permainan olahraga. Permainan pasif meliputi kegiatan bermain sambil membaca, mendengarkan radio dan menonton televisi. Penulis melihat kegiatan bermain sambil belajar dengan media pembelajaran CD Interaktif bisa masuk pada jenis permainan aktif dan pasif. Terbilang aktif karena pengguna ikut terlibat dalam permainan. Terbilang pasif karena pengguna tidak melakukan banyak pergerakan karena interaksi lebih banyak terjadi antara pengguna dengan komputer.

\subsection{Huruf Hiragana}

Abjad dalam bahasa Jepang terdiri dari : Hiragana, Katakana, Kanji, dan Romaji. Hiragana dipakai untuk menuliskan kata-kata asli bahasa Jepang dan dipakai untuk menggantikan kata-kata dari Kanji. Katakana dipakai untuk menuliskan kata-kata yang berasal dari bahasa asing, nama orang asing, nama negeri asing, nama kota luar negeri dan lain-lainnya yang bukan Jepang. Kanji dipakai untuk menuliskan kata-kata yang merupakan serapan dari abjad Cina. Romaji adalah huruf latin (26 huruf alphabet).

Seperti yang dipaparkan oleh Tirtobisono (1996) bahwa Hiragana (ひらがな、平仮名) adalah suatu cara penulisan bahasa Jepang dan mewakili sebutan suku kata. Pada masa silam, Hiragana juga dikenali sebagai onna de (女手) atau 'tulisan wanita' karena biasa digunakan oleh kaum wanita. Kaum lelaki pada masa itu menulis menggunakan tulisan Kanji dan Katagana. Huruf Hiragana mulai digunakan secara luas pada abad ke-10 Masehi.

\subsubsection{Kegunaan Huruf Hiragana}

Kegunaan huruf Hiragana disampaikan oleh Ambarwati (2004) yaitu digunakan untuk kata-kata bahasa Jepang dimana Kanji tidak tidak dapat dipakai secara mudah, kata-kata yang merupakan simbol sebuah bunyi, akhir kata-kata yang terkonjungsi seperti kata kerja, kata sifat, partikel atau kata sandang, kata kerja bantu, dan yang sejenis. Demikian juga kata ganti, kata keterangan, dan kata sambung serta nama tumbuhan dan hewan lebih baik ditulis dengan bentuk Hiragana. Contoh kegunaan Hiragana antara lain :

1. Menulis akhiran kata (okurigana, 送り仮名). Contoh: okuru (mengirim) ditulis: 送る. Yang bercetak tebal itulah okurigana

2. Menulis kata keterangan (adverb), beberapa kata benda (noun) dan kata sifat (adjective) 
3. Perkataan-perkataan dimana Kanjinya tidak diketahui atau sudah lama tidak digunakan

4. Menulis bahan bacaan anak-anak seperti buku teks, teks lagu, animasi (anime), animasi yang dikomikkan (animanga), dan komik (manga)

5. Menulis furiragana, dikenal juga dengan rubi, yaitu teks kecil di atas Kanji, yang menandakan bagaimana suatu kata dibaca.

\subsubsection{Aturan Menulis Huruf Hiragana}

Tiga aturan utama dalam menulis huruf Hiragana antara lain :

1. Pertama-tama, susun huruf untuk membentuk kata yang diinginkan (sudah jelas)

2. Konsonan tebal diwakili oleh huruf 'tsu' kecil Contoh: はっきり $=(\text { ha })_{(\mathrm{tsu})}(\mathrm{ki})(\mathrm{ri})=$ hakkiri

3. Vokal panjang ditulis dengan menambahkan huruf terkait Contoh: おかあさん=(o)(ka)(a)(sa)(n)= okaa-san

Materi huruf Hiragana yang dipelajari dalam perancangan media pembelajaran mencakup 5 vokal (a, i, u, e, o), 2 semivokal (y, w), dan 14 konsonan (k, s, t, n, h, m, r, g, z, d, b, p, c, f)

\subsection{Aplikasi Perancangan}

Penulis menggunakan aplikasi Adobe Flash pada proses perancangan CD Interaktif. Menurut Tim Peneliti dan Pengembangan Wahana Komputer (2004), Fitur-fitur yang dimiliki Adobe Flash dapat digunakan untuk pembuatan, pengolahan, serta manipulasi berbagai jenis data meliputi audio, video, gambar bitmap dan vektor, teks serta data. Penggunaan Adobe Flash juga cukup populer dikalangan para pembuat animasi.

Bahasa pemrograman yang penulis gunakan adalah Action Script 2.0. Nugroho (2011) menyampaikan bahwa bahwa Adobe ActionScript merupakan bahasa pemrograman yang bekerja di dalam platform Adobe Flash. ActionScript memang dibangun sebagai cara untuk mengembangkan pemrograman interaktif secara efisien menggunakan platform aplikasi Adobe Flash ActionScript. Penggunaannya mulai dari animasi yang sederhana sampai dengan yang kompleks, juga dalam penggunaan data, dan aplikasi interface yang interaktif. Seperti apa yang disampaikan Madcoms (2001), perintah ActionScript adalah suatu perintah yang dapat menghasilkan suatu aksi atau gerakan pada objek. ActionScript digunakan untuk membuat animasi yang lebih kompleks dan interaktif, sehingga lebih menarik bagi penikmat animasi 


\section{METODOLOGI DAN KONSEP PERANCANGAN}

\subsection{Metodologi}

Metode yang digunakan pada penelitian ini mengikuti model penelitian dan pengembangan. Penulis melakukan kajian pustaka untuk mendapatkan data sekunder yang meliputi pengetahuan tentang perancangan, media pembelajaran berbasis komputer, psikologi anak terkait interaksinya dengan media, dan materi pembelajaran yaitu huruf Hiragana. Kajian tentang penelitian terdahulu terkait media pembelajaran juga dilakukan untuk melihat potensi pengembangan media pembelajaran berupa CD Interaktif. Analisis deskriptif dilakukan pada data sekunder. Dari kajian pustaka tentang psikologi anak terkait interaksinya dengan media, dan kajian pustaka tentang media pembelajaran berbasis komputer diperoleh fakta mengenai keunggulan media CD interaktif sebagai media alternatif pembelajaran. Hasil kajian pustaka tentang Hiragana digunakan sebagai materi utama media pembelajaran CD Interaktif. Pemilihan model tutorial dan instructional games dilakukan atas hasil kajian pustaka bahwa model tersebut dianggap paling menarik minat anak untuk belajar. Selanjutnya, CD interaktif model tutorial dan instructional games disampaikan dengan cara bercerita (storytelling). Storytelling ini menjadi konsep perancangan yang menambah daya tarik media pembelajaran.

\subsection{Konsep perancangan}

Penyampaian materi pembelajaran huruf Hiragana adalah dengan konsep bercerita (storytelling). Dalam proses pembelajaran dengan CD interaktif model tutorial dan instructional games dengan konsep storytelling akan membantu anak untuk tidak hanya mengutamakan kemampuan otak kiri, tetapi juga otak kanan. Secara umum semua anak-anak senang mendengarkan storytelling, baik anak balita, usia sekolah dasar, maupun yang telah beranjak remaja bahkan orang dewasa. Kebiasaan anak-anak untuk bermain game dalam platform yang kurang berunsur edukasi seperti game-game Playstation bisa direduksi ketika mereka mendapatkan pilihan media lain yang lebih bermanfaat dalam pendidikan. Konsep CD Interaktif dalam penyampaian storytelling tidak hanya menyampaikan pengajaran tentang huruf Hiragana, tetapi juga menyampaikan pendidikan tentang watak/karakter yang direpresentasikan pada sosok protagonis : Kenji (lihat Gambar 3.1) dan antagonis : Kappa (lihat Gambar 3.2) dan juga tentang budaya Jepang, khususnya mitologi Jepang.

Storytelling yang disampaikan : Ninja Kenji (10 tahun) adalah seorang anak ninja yang menggunakan baju merah hati / merah SD. Ia berkelana untuk memberantas kejahatan. Kappa adalah sosok jahat, yang biasa menebar teror kejahatan. Ninja Kenji harus memberantas kejahatan yang dilakukan oleh Kappa. Dalam aksinya, Ninja Kenji memerlukan bantuan dari peserta didik untuk memecahkan misteri setiap sandi huruf Hiragana yang ada. Sebelum berpetualang, Ninja Kenji mendapat pembekalan ilmu oleh guru (Sensei) dan beberapa makhluk mitologi Jepang yaitu Kitsune, Konak Jiji, Ameterasu, 
Yatagarasu, dan Shukaku. Setiap sandi huruf Hiragana yang terpecahkan akan merubah bentuk dan sifat Kappa sedikit demi sedikit menjadi baik.

Konsep setting ruang dan waktu penting diciptakan untuk mengajak pengguna CD interaktif lebih terlibat dalam cerita. Setting berlokasi di kota Fujiyoshida, Prefektur Yamanashi, Wilayah Chubu, Kepulauan Honshu, Negara Jepang. Petualangan berlokasi di bantaran sungai Sagami yang berhulu di danau Yamanaka dengan menggunakan waktu pagi hingga sore hari dalam setting waktu masa dimana entitas mitologi Jepang hidup (lihat Gambar 3.3).

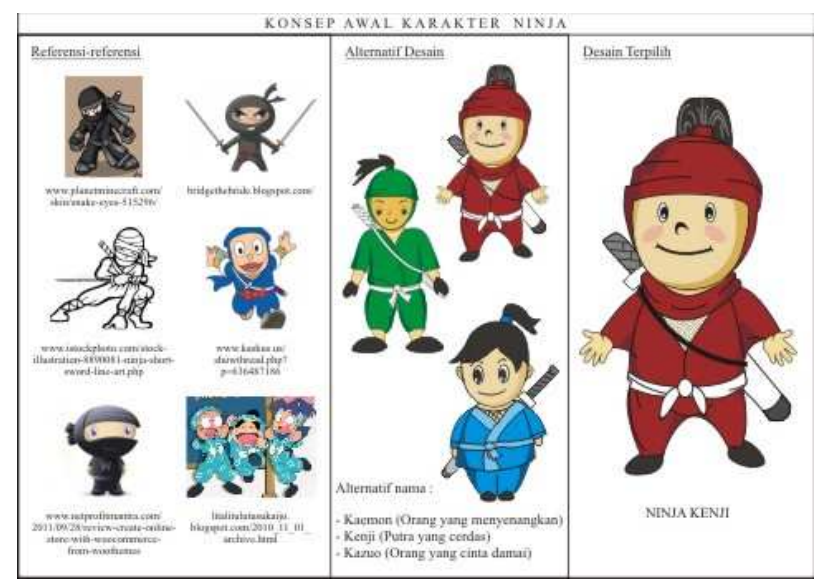

Gambar 3.1 Konsep Karakter Protagonis : Ninja Kenji

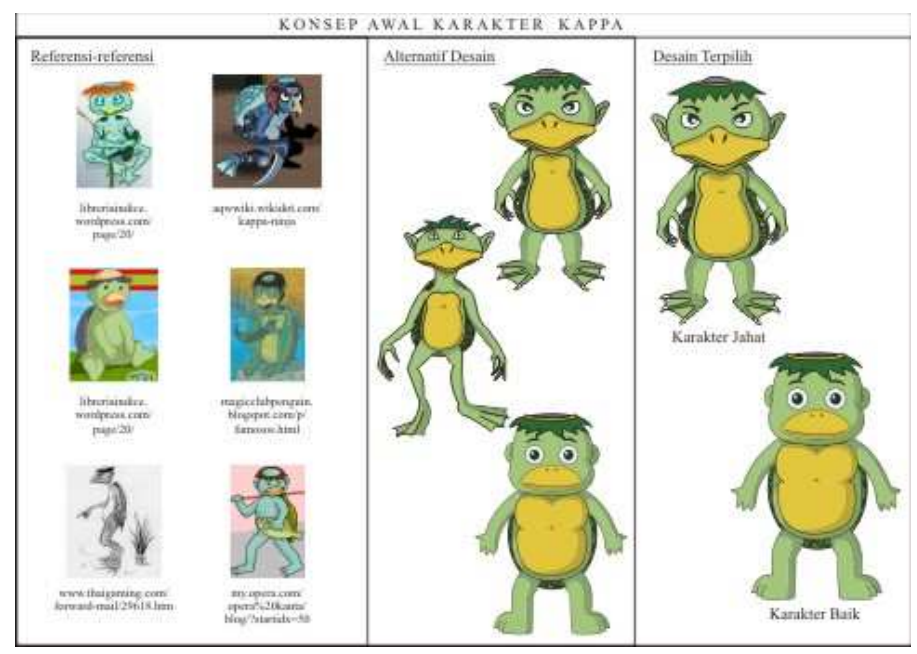

Gambar 3.2 Konsep Karakter Antagonis : Kappa 


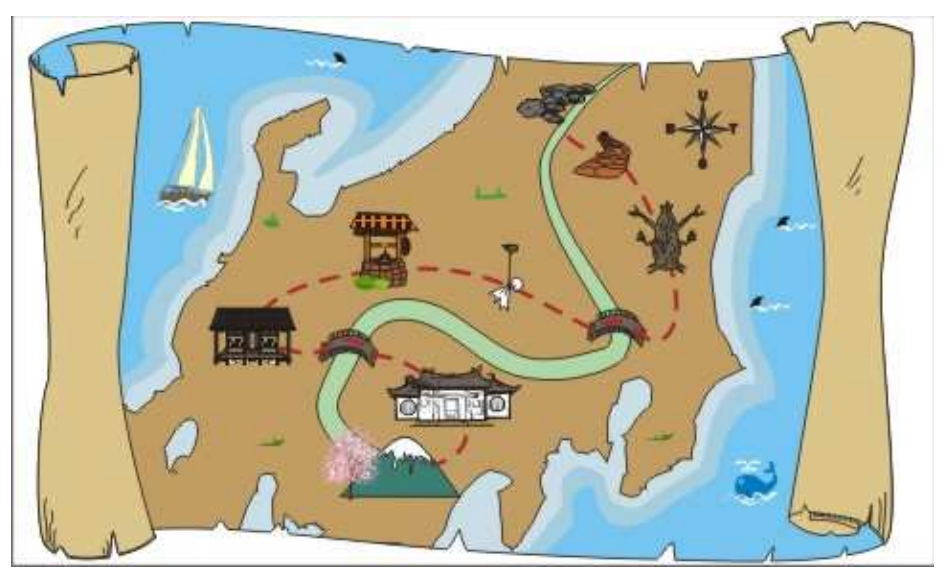

Gambar 3.3 Setting Ruang dan waktu Petualangan Kenji

Ninja Kenji memulai petualangan dari Danau Yamanaka di kaki gunung Fuji ke arah utara melalui sekolah Ninjutsu, rumah Kitsune, sumur tua, Teruteru bozu (penangkal hujan), pohon Betula pubescens, jalan berbatu tanah bata, dan terakhir batuan di hilir sungai Sagami (lihat Gambar 3.4).

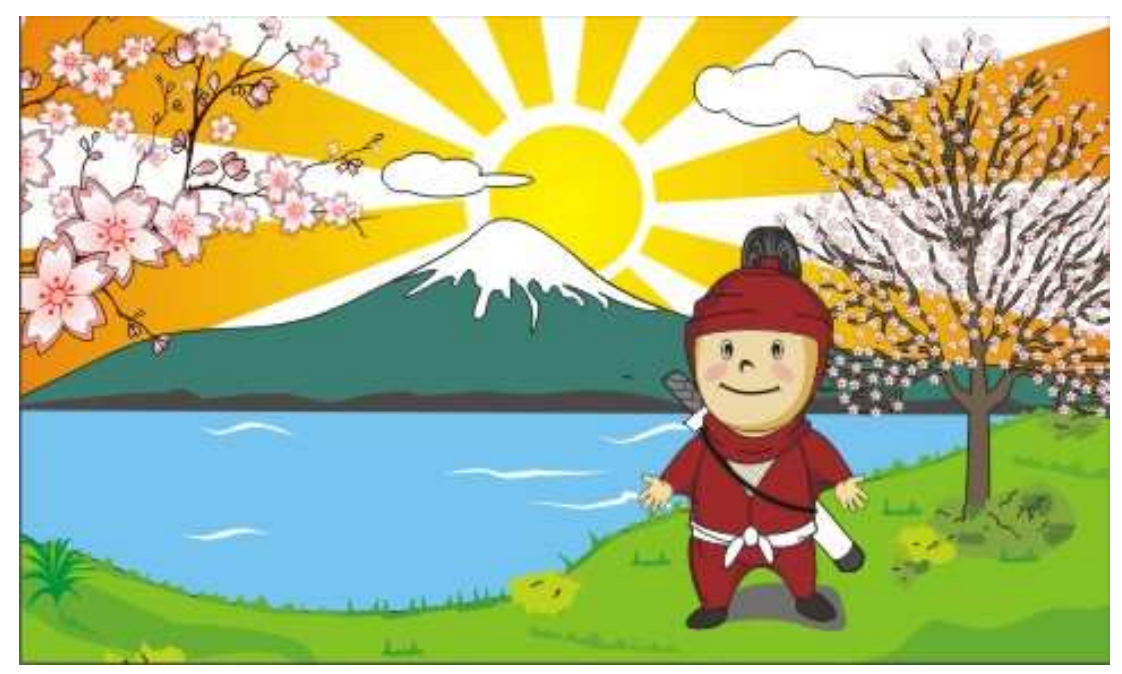

Gambar 3.4 Setting Ruang dan Waktu Ninja Kenji

\section{HASIL DAN PEMBAHASAN}

Media pembelajaran berbasis komputer pembelajaran huruf Hiragana dikembangkan berdasarkan hasil analisis kebutuhan. Dari proses 1) Pengumpulan data aktual dan faktual dan (2) Analisis, didapatkan pemilihan penggunaan Model Tutorial dan Instructional Games sebagai model pembelajaran berbasis komputer CD Interaktif. Dari proses tersebut juga ditentukan pemilihan materi-materi 
beserta menu-menu yang akan disampaikan pada media CD Interaktif. Pada proses 3) Perancangan, menggunakan segala aset desain seperti image karakter, setting, animasi dan Background Music, yang dikomposisikan dan diedit menggunakan Adobe Flash dengan bahasa pemrograman Action Script 2.0. Pada tahapan 4) Evaluasi, dilakukan terhadap kesesuaian antara penggunaan aset-aset desain pada perancangan dengan teori-teori pada kajian pustaka dan konsep perancangan. Evaluasi menghasilkan kesimpulan. Keseluruhan rancangan CD interaktif pembelajaran huruf Hiragana ini digambarkan dalam bentuk alur menu yang bisa dilihat pada Gambar 4.1. 
Gambar 4.1 Alur Menu Pembelajaran Huruf Hiragana pada Media CD Interaktif

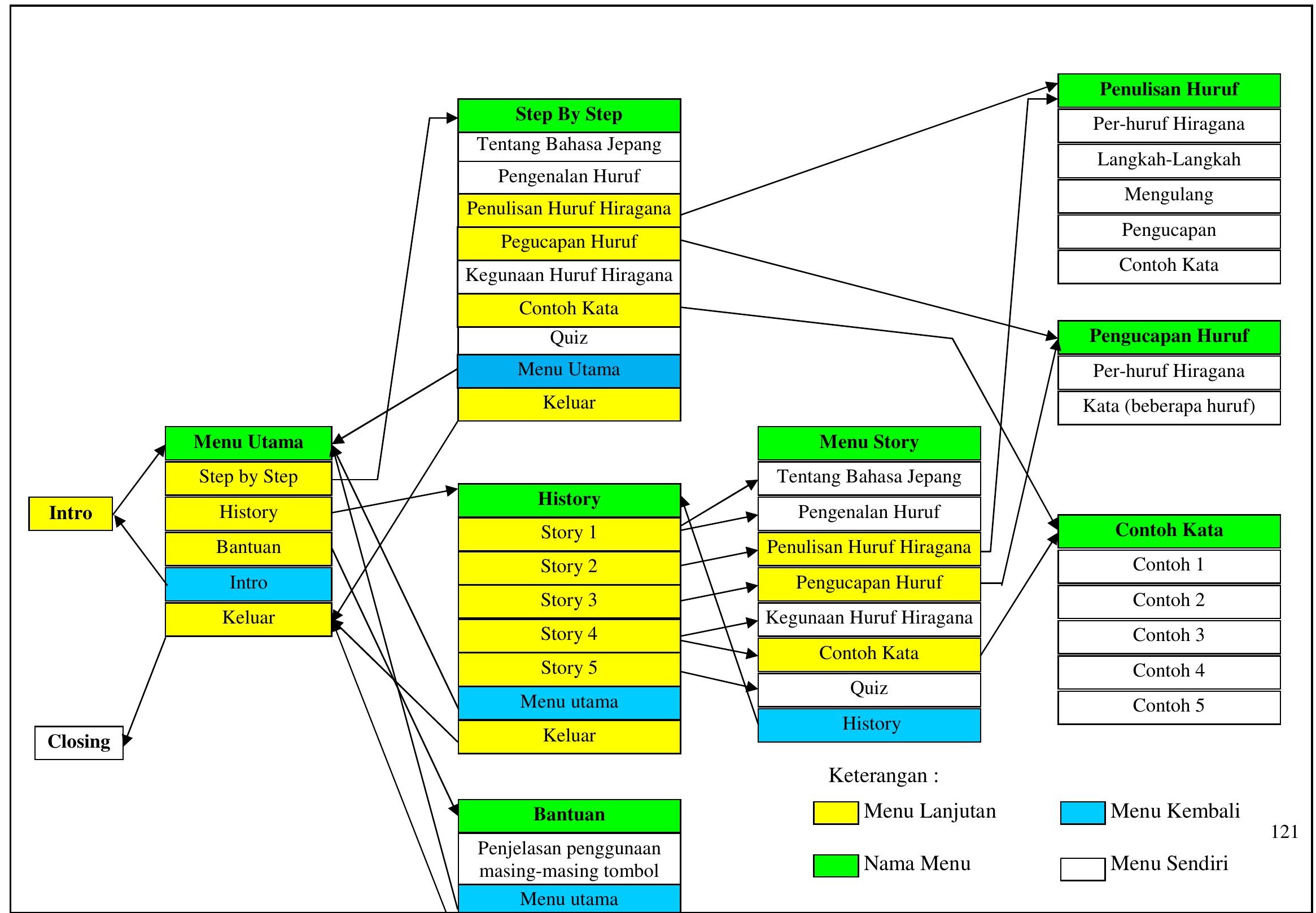


ISSN 2089-8673

Jurnal Nasional Pendidikan Teknik Informatika (JANAPATI)

Volume 2, Nomor 2, Juli 2013

\section{KESIMPULAN}

Penelitian dilaksanakan dengan menggunakan model penelitian dan perancangan yang meliputi tahap-tahap: 1) pengumpulan data aktual dan faktual; 2) analisis; 3) perancangan CD Interaktif; 4) evaluasi. Perancangan CD interaktif pembelajaran huruf Hiragana yang menarik bagi siswa kelas IV SD adalah yang menggunakan model pembelajaran model tutorial dan instructional games. Materi pembelajaran huruf Hiragana disampaikan dengan konsep bercerita (storytelling). Dalam proses pembelajaran dengan CD interaktif model tutorial dan instructional games dengan konsep storytelling akan membantu anak untuk tidak hanya mengutamakan kemampuan otak kiri yang cenderung berpikir rasional, tetapi juga otak kanan dengan kecenderungan berpikir kreatif dan imajinatif. Secara umum, semua anak-anak senang mendengarkan storytelling, baik anak balita, usia sekolah dasar, maupun yang telah beranjak remaja bahkan orang dewasa.

\section{DAFTAR PUSTAKA}

Ambarwati, P. (2004). Bahasa Jepang Sehari-hari (Japanese For ToDay). Jakarta : Grasindo

Bandura, A. (1977). Social Learning Theory. Upper Saddle River, NJ: Prentice Hall

Barnard, M. (1998). Art, Design and Visual Culture. New York :St.Martin's Press

Chandra, T. (1976). Bahasa Jepang Sehari-hari. Jakarta : Evergreen Japanese Course

Chulsum, U. (2006). Kamus Besar Bahasa Indonesia I. Surabaya : Yoshiko Press

Davidson, M. (2004). A Phenomenological evaluation:using storytelling as a primary teaching method. Nurse Education and Practise 4

Darmawan, H. (2012). How To Make Comics-Menurut Para Master Komik Dunia. Jakarta : Plotpoint publishing

Dimyati dan Mudjiono (2002). Belajar dan Pembelajaran. Jakarta: PT. Rineka Cipta.

Fathurrahmar, F. (2011). Pengertian Multimedia / Interaktif. Tersedia pada : http://www.multimedia-interaktif.com/. (diakses tanggal 28 April 2012)

Hadi, M. S. (2009). Belajar Huruf Hiragana. Tersedia pada: http://www.ppitokodai.org/index.php?option=com_content\&view=article\&id=1 31:belajar-huruf-hiragana\&catid=20:artikel\&Itemid=74. (diakses tanggal 25 April 2012) 
ISSN 2089-8673

Jurnal Nasional Pendidikan Teknik Informatika (JANAPATI)

Volume 2, Nomor 2, Juli 2013

Kridalaksana, H. (2005). Pesona Bahasa : Langkah Awal Memahami Linguistik. Jakarta : Gramedia Pustaka Utama

Krisnawan, S. R. (2009). Pengertian dan Ciri-ciri Pembelajaran. Tersedia pada: http://krisna1.blog.uns.ac.id/2009/10/19/pengertian-dan-ciri-ciri-pembelajaran/. (Diakses pada 25 April 2012)

Lembaga Psikologi Episentrum (2010). Pengaruh Permainan Pada Perkembangan Anak.

Tersedia pada : http://episentrum.com/artikel-psikologi/pengaruh-permainan-padaperkembangan-anak/ (Diakses pada 25 April 2012)

Lembaga Psikologi Episentrum (2010). Story Telling. Tersedia pada : http://episentrum.com/layanan/story-telling/ (Diakses pada 25 April 2012)

Madcoms (2011). Kupas Tuntas Adobe Flash Profesional CS5. Yogyakarta : Andi Offset

Nugroho, A. H. (2011). Pengenalan Flash dan actionsript 3. Tersedia pada : http://lecturer.ukdw.ac.id/cnuq/wp-content/uploads/animasi/bab1.pdf. (diakses tanggal 25 April 2012)

Ogawa, I. (2008). Minna no Nihongo Shokyu I : Indonesian version. Tokyo : International Mutual Activity Foundation (IMAF) Press

Reskiwahyudi, U. (2011). Pengaruh Penggunaan Media CD Interaktif Terhadap Hasil Belajar Kimia Siswa SMA Negeri 2 Maros (Studi Pokok Materi Sifat Koligatif Larutan. Tersedia pada : reskiwahyudi.blogspot.com/2011/06/pengaruh-penggunaan-media-cdinteraktif.html. (Diakses pada 25 April 2012)

Riswan, (2009). Pengertian Pembelajaran Menurut Beberapa Ahli. Tersedia pada : http://www.scribd.com/doc/50015294/13/B-Pengertian-pembelajaran-menurutbeberapa-ahli.html (Diakses pada 25 April 2012)

Setemen K., dkk. (2004). Pembuatan Media Pembelajaran Pengetahuan Alat Dapur Berbasis Multimedia Pada Jurusan Boga Perhotelan. Bali : IKIP N Singaraja.

Sudatha, I G. W. (2010). Pengembangan Media Pembelajaran Berbasis Komputer Pada Mata Pelajaran Ilmu Pengetahuan Sosial Kelas VII Untuk Optimalisasi Hasil Belajar. Prosiding Seminar Nasional Pendidikan Teknik Informatika (SENAPATI) 2010 
ISSN 2089-8673

Jurnal Nasional Pendidikan Teknik Informatika (JANAPATI)

Volume 2, Nomor 2, Juli 2013

Sudjianto (1996). Gramatika Bahasa Jepang Modern Seri A. Jakarta : Kesaint Blanc

Tim Peneliti dan Pengembangan Wahana Komputer (2004). Pembuatan CD Interaktif dengan Macromedia Flash MX Professional. Salemba Imfotek: Jakarta.

Tirtobisono, Y. (1996). Cepat Menguasai Bahasa Jepang. Surabaya : Indah Surabaya

Wahid, F. (2005). Kamus Istilah Teknologi II. Yogyakarta : Andi Yogyakarta

Widagdo. (2005). Desain dan Kebudayaan. Bandung : Institut Teknologi Bandung 